\title{
ANALISIS KESTABILAN MODEL LOTKA-VOLTERRA
}

\author{
TRI YULIADI M, AHMAD IQBAL BAQI \\ Program Studi Matematika, \\ Fakultas Matematika dan Ilmu Pengetahuan Alam, Universitas Andalas, \\ Kampus UNAND Limau Manis Padang, Indonesia. \\ email : pikiranbungsu124@gmail.com
}

\begin{abstract}
Abstrak. Interaksi antar makhluk hidup terdapat bermacam-macam, salah satunya yaitu interaksi makhluk hidup dalam memperoleh makanan. Interaksi antara spesies dalam memperoleh makanan tidak hanya terjadi pada satu spesies namun juga terjadi antara dua spesies yang berkompetisi memperebutkan makanan yang sama. Persaingan antar spesies dalam memperoleh makanan dapat digambarkan dengan model LotkaVolterra. Akibat dari interaksi ini terdapat dua kemungkinan yaitu kedua spesies yang berkomprtisi dapat hidup berdampingan atau salah satu mengalami kepunahan. Agar salah satu spesies tidak mengalami kepunahan, maka dalam penelitian ini dilakukan analisis kestabilan titik tetap dari model Lotka-Volterra dilengkapi simulasi.
\end{abstract}

Kata Kunci: Laju Pertumbuhan Kompetisi Dua Spesies, model Lotka-Volterra, Kestabilan Titik Tetap

$\begin{array}{lll}\text { Diterima } & : & \text { 29 November } 2018 \\ \text { Direvisi } & : & 3 \text { Desember 2018 } \\ \text { Dipublikasikan } & : & 30 \text { Desember 2018 }\end{array}$

\section{Pendahuluan}

Dalam kehidupan alam, setiap makhluk hidup tidak dapat hidup sendiri dan membutuhkan makhluk hidup lain. Setiap makhluk hidup menjalani hidup secara bersama dan saling berinteraksi satu dengan yang lainnya. Terdapat bermacam interaksi antar makhluk hidup baik interaksi dalam satu spesies maupun interaksi antara satu spesies dengan spesies lain. Salah satu interaksi makhluk hidup yang terjadi yaitu interaksi antar spesies dalam memperoleh makanan.

Interaksi antar spesies dalam memperoleh makanan digambarkan dengan model Lotka-Volterra. Model ini pertama kali dikembangkan oleh Alfred J. Lotka pada tahun 1925 dan kemudian dilanjutkan lagi oleh seorang matematikawan Italia yaitu Vito Volterra pada tahun 1926 [3]. Model tersebut mempunyai asumsi dasar bahwa model pertumbuhan spesies terhadap ketersediaan makanannyalah model eksponensial. Model interaksi spesies terhadap makanannya banyak mengalami perkembangan dengan menggunakan model yang lebih kompleks yaitu model pertumbuhan logistik yang menggambarkan interaksi antara spesies terhadap makanannya yang dipengaruhi oleh daya dukung lingkungan yaitu:

$$
\dot{N}=r N\left(1-\frac{N}{K}\right)
$$


dimana $\dot{N}=\frac{d N}{d t}, N(t)$ adalah jumlah populasi spesies pada saat $t, r$ merupakan laju pertumbuhan dari spesies dan $K$ adalah daya dukung lingkungan untuk spesies.

Pada kenyataannya, interaksi antara spesies terhadap makanannya tidak hanya terjadi pada satu spesies tetapi bisa terjadi interaksi antara dua spesies yang berkompetisi memperebutkan makanan yang sama. Interaksi yang terjadi mengakibatkan dua spesies saling berkompetisi untuk bertahan hidup. Akibat dari interaksi yang terjadi spesies 1 dan spesies 2 bisa hidup berdampingan atau salah satu spesies mengalami kepunahan terhadap ketersediaan makanannya. Untuk itu dari interaksi dua spesies akan dianalisis kestabilan pada titik tetap agar salah satu spesies tidak mengalami kepunahan.

\section{Pembahasan}

Model Lotka-Volterra dikembangkan berdasarkan model pertumbuhan dua spesies. Dalam [5] dinyatakan bahwa pertumbuhan kedua spesies masing-masing memenuhi persamaan diferensial berikut ini:

$$
\begin{aligned}
& \frac{d N_{1}}{d t}=r_{1} N_{1}\left(1-\frac{N_{1}}{K_{1}}\right), \\
& \frac{d N_{2}}{d t}=r_{2} N_{2}\left(1-\frac{N_{2}}{K_{2}}\right) .
\end{aligned}
$$

Jika keduanya berkompetisi memperebutkan sumber daya, Lotka-Volterra menggunakan model persamaan diferensial berikut:

$$
\begin{aligned}
& \frac{d N_{1}}{d t}=r_{1} N_{1}\left(1-\frac{N_{1}+\beta_{12} N_{2}}{K_{1}}\right), \\
& \frac{d N_{2}}{d t}=r_{2} N_{2}\left(1-\frac{N_{2}+\beta_{21} N_{1}}{K_{2}}\right) .
\end{aligned}
$$

Titik tetap dari model (2.2) ditentukan sebagai berikut.

$$
\begin{aligned}
& r_{1} N_{1}\left(1-\frac{N_{1}+\beta_{12} N_{2}}{K_{1}}\right)=0 \\
& r_{2} N_{2}\left(1-\frac{N_{2}+\beta_{21} N_{1}}{K_{2}}\right)=0 .
\end{aligned}
$$

Solusi titik tetap untuk model (2.2) adalah

1. $\left(N_{1}, N_{2}\right)=(0,0)$

2. $\left(N_{1}, N_{2}\right)=\left(0, K_{2}\right)$

3. $\left(N_{1}, N_{2}\right)=\left(K_{1}, 0\right)$

4. $\left(N_{1}, N_{2}\right)=\left(\frac{K_{1}-\beta_{12} K_{2}}{1-\beta_{21} \beta_{12}}, \frac{K_{2}-\beta_{21} K_{1}}{1-\beta_{21} \beta_{12}}\right)$.

Selanjutnya akan ditentukan pelinieran dari sistem (2.2) di sekitar titik tetap- 
titik tetap di atas. Matriks Jacobian dari sistem (2.2) adalah

$$
\begin{aligned}
J_{*}= & \left(\begin{array}{ll}
\frac{\partial \dot{N}_{1}}{\partial N_{1}} & \frac{\partial \dot{N}_{1}}{\partial N_{2}} \\
\frac{\partial N_{2}}{\partial N_{1}} & \frac{\partial N_{2}}{\partial N_{2}}
\end{array}\right) \\
= & \left(\begin{array}{cc}
r_{1}\left(1-\frac{2 N_{1}+\beta_{12} N_{2}}{K_{1}}\right) & -\frac{r_{1} N_{1} \beta_{12}}{K_{1}} \\
-\frac{r_{2} \beta_{21} N_{2}}{K_{2}} & r_{2}\left(1-\frac{2 N_{2}+\beta_{21} N_{1}}{K_{2}}\right)
\end{array}\right) .
\end{aligned}
$$

Matriks Jacobian pada titik tetap $(0,0)$ adalah

$$
J_{*}(0,0)=\left(\begin{array}{cc}
r_{1} & 0 \\
0 & r_{2}
\end{array}\right) .
$$

Nilai eigen dari $J_{*}(0,0)$ adalah

$$
\lambda_{1}=r_{1} \quad \text { dan } \quad \lambda_{2}=r_{2}
$$

Karena $r_{1}>0$ dan $r_{2}>0$ maka potret fase model $(2.2)$ di sekitar titik tetap $(0,0)$ berbentuk node tidak stabil.

Matriks Jacobian pada titik tetap $\left(0, K_{2}\right)$ adalah

$$
J_{*}\left(0, K_{2}\right)=\left(\begin{array}{cc}
r_{1}\left(1-\frac{\beta_{12} K_{2}}{K_{1}}\right) & 0 \\
-r_{2} \beta_{21} & -r_{2}
\end{array}\right) .
$$

Nilai eigen dari $J_{*}\left(0, K_{2}\right)$ adalah

$$
\lambda_{1}=r_{1}\left(1-\frac{\beta_{12} K_{2}}{K_{1}}\right) \quad \text { dan } \quad \lambda_{2}=-r_{2} .
$$

Dari (2.6) diperoleh jika $\frac{\beta_{12} K_{2}}{K_{1}}>1$, maka nilai eigen dari $J_{*}\left(0, K_{2}\right)$ adalah negatif, sehingga potret fase dari model $(2.2)$ di sekitar titik tetap $\left(0, K_{2}\right)$ berbentuk node stabil. Sebaliknya, jika $\frac{\beta_{12} K_{2}}{K_{1}}<1$, maka nilai eigen dari $J_{*}\left(0, K_{2}\right)$ berlawanan tanda, sehingga potret fase dari model (2.2) di sekitar titik tetap $\left(0, K_{2}\right)$ berbentuk saddle node.

Matriks Jacobian pada titik tetap $\left(K_{1}, 0\right)$ adalah

$$
J_{*}\left(K_{1}, 0\right)=\left(\begin{array}{cc}
-r_{1} & -r_{1} \beta_{12} \\
0 & r_{2}\left(1-\frac{\beta_{21} K_{1}}{K_{2}}\right)
\end{array}\right) .
$$

Nilai eigen dari $J_{*}\left(K_{1}, 0\right)$ adalah

$$
\lambda_{1}=r_{2}\left(1-\frac{\beta_{21} K_{1}}{K_{2}}\right) \quad \text { dan } \quad \lambda_{2}=-r_{1} .
$$

Dari (2.7) diperoleh jika $\frac{\beta_{21} K_{1}}{K_{2}}>1$, maka nilai eigen dari $J_{*}\left(K_{1}, 0\right)$ adalah negatif, sehingga potret fase dari model $(2.2)$ di sekitar titik tetap $\left(K_{1}, 0\right)$ berbentuk node stabil. Sebaliknya, jika $\frac{\beta_{21} K_{1}}{K_{2}}<1$, maka nilai eigen dari $J_{*}\left(K_{1}, 0\right)$ berlawanan tanda, sehingga potret fase dari model $(2.2)$ di sekitar titik tetap $\left(K_{1}, 0\right)$ berbentuk saddle node. 
Selanjutnya matriks Jacobian pada titik tetap $\left(\frac{K_{1}-\beta_{12} K_{2}}{1-\beta_{21} \beta_{12}}, \frac{K_{2}-\beta_{21} K_{1}}{1-\beta_{21} \beta_{12}}\right)$ adalah

$$
J_{*}\left(\frac{K_{1}-\beta_{12} K_{2}}{1-\beta_{21} \beta_{12}}, \frac{K_{2}-\beta_{21} K_{1}}{1-\beta_{21} \beta_{12}}\right)=\left(\begin{array}{cc}
r_{1}\left(\frac{-K_{1}+\beta_{12} K_{2}}{K_{1}\left(1-\beta_{12} \beta_{21}\right)}\right) & -r_{1} \frac{K_{1} \beta_{12}-\beta_{12} K_{2} \beta_{12}}{K_{1}\left(1-\beta_{21} \beta_{12}\right)} \\
-r_{2} \frac{K_{2} \beta_{21}-\beta_{21} \beta_{21} K_{1}}{K_{2}\left(1-\beta_{21} \beta_{12}\right)} & r_{2}\left(\frac{-K_{2}+\beta_{21} K_{1}}{K_{2}\left(1-\beta_{12} \beta_{21}\right)}\right)
\end{array}\right)
$$

Nilai eigen dari $J_{*}\left(\frac{K_{1}-\beta_{12} K_{2}}{1-\beta_{21} \beta_{12}}, \frac{K_{2}-\beta_{21} K_{1}}{1-\beta_{21} \beta_{12}}\right)$ adalah

$$
\lambda_{1,2}=\frac{-b \pm \sqrt{b^{2}-4 a c}}{2 a}
$$

dimana

$$
\begin{aligned}
a & =\left(1-\beta_{12} \beta_{21}\right) \\
b & =-\left(r_{1}\left(\beta_{12} \frac{K_{2}}{K_{1}}-1\right)+r_{2}\left(\beta_{21} \frac{K_{1}}{K_{2}}-1\right)\right) \\
c & =\left(1-\beta_{12} \beta_{21}\right)\left[r_{1}\left(\beta_{12} \frac{K_{2}}{K_{1}}-1\right) r_{2}\left(\beta_{21} \frac{K_{1}}{K_{2}}-1\right)\right] \\
b^{2}-4 a c & =\left(-\left(r_{1}\left(\beta_{12} \frac{K_{2}}{K_{1}}-1\right)+r_{2}\left(\beta_{21} \frac{K_{1}}{K_{2}}-1\right)\right)\right)^{2} \\
& -4\left(1-\beta_{12} \beta_{21}\right)^{2}\left[r_{1}\left(\beta_{12} \frac{K_{2}}{K_{1}}-1\right) r_{2}\left(\beta_{21} \frac{K_{1}}{K_{2}}-1\right)\right]
\end{aligned}
$$

Dari (2.9) diperoleh jika $\frac{\beta_{21} K_{1}}{K_{2}}<1$ dan $\frac{\beta_{12} K_{2}}{K_{1}}<1$, maka nilai eigen dari $J_{*}\left(\frac{K_{1}-\beta_{12} K_{2}}{1-\beta_{21} \beta_{12}}, \frac{K_{2}-\beta_{21} K_{1}}{1-\beta_{21} \beta_{12}}\right)$ adalah negatif, sehingga potret fase dari model (2.2) di sekitar titik tetap $\left(\frac{K_{1}-\beta_{12} K_{2}}{1-\beta_{21} \beta_{12}}, \frac{K_{2}-\beta_{21} K_{1}}{1-\beta_{21} \beta_{12}}\right)$ berbentuk node stabil. Sebaliknya jika $\frac{\beta_{21} K_{1}}{K_{2}}>1$ dan $\frac{\beta_{12} K_{2}}{K_{1}}>1$, maka nilai eigen dari $J_{*}\left(\frac{K_{1}-\beta_{12} K_{2}}{1-\beta_{21} \beta_{12}}, \frac{K_{2}-\beta_{21} K_{1}}{1-\beta_{21} \beta_{12}}\right)$ adalah berlawanan tanda, sehingga potret fase dari model (2.2) di sekitar titik tetap $\left(\frac{K_{1}-\beta_{12} K_{2}}{1-\beta_{21} \beta_{12}}, \frac{K_{2}-\beta_{21} K_{1}}{1-\beta_{21} \beta_{12}}\right)$ berbentuk saddle node.

\section{Kesimpulan}

Dalam model tersebut didapatkan empat titik tetap yaitu:

(i) Titik $(0,0)$ dengan nilai eigen $\lambda_{1}=r_{1}$ dan $\lambda_{2}=r_{2}$,

(ii) Titik $\left(0, K_{2}\right)$ dengan nilai eigennya $\lambda_{1}=-r_{2}$ dan $\lambda_{2}=r_{1}\left(1-\frac{\beta_{12} K_{2}}{K_{1}}\right)$,

(iii) Titik $\left(K_{1}, 0\right)$ dengan nilai eigennya $\lambda_{1}=-r_{1}$ dan $\lambda_{2}=r_{2}\left(1-\frac{\beta_{21} K_{1}}{K_{2}}\right)$,

(iv) Titik $\left(\frac{K_{1}-\beta_{12} K_{2}}{1-\beta_{21} \beta_{12}}, \frac{K_{2}-\beta_{21} K_{1}}{1-\beta_{21} \beta_{12}}\right)$ dengan nilai eigennya $\lambda_{1}$ dan $\lambda_{2}$ yakni

$$
\lambda_{1,2}=\frac{-b \pm \sqrt{b^{2}-4 a c}}{2 a}
$$


dimana

$$
\begin{aligned}
a & =\left(1-\beta_{12} \beta_{21}\right) \\
b & =-\left(r_{1}\left(\beta_{12} \frac{K_{2}}{K_{1}}-1\right)+r_{2}\left(\beta_{21} \frac{K_{1}}{K_{2}}-1\right)\right) \\
c \quad & \left(1-\beta_{12} \beta_{21}\right)\left[r_{1}\left(\beta_{12} \frac{K_{2}}{K_{1}}-1\right) r_{2}\left(\beta_{21} \frac{K_{1}}{K_{2}}-1\right)\right] \\
b^{2}-4 a c & =\left(-\left(r_{1}\left(\beta_{12} \frac{K_{2}}{K_{1}}-1\right)+r_{2}\left(\beta_{21} \frac{K_{1}}{K_{2}}-1\right)\right)\right)^{2} \\
& -4\left(1-\beta_{12} \beta_{21}\right)^{2}\left[r_{1}\left(\beta_{12} \frac{K_{2}}{K_{1}}-1\right) r_{2}\left(\beta_{21} \frac{K_{1}}{K_{2}}-1\right)\right]
\end{aligned}
$$

\section{Ucapan Terima kasih}

Penulis mengucapkan terima kasih kepada bapak Dr. Mahdhivan Syafwan, bapak Dr. Admi Nazra, bapak Dr. Jenizon yang telah memberikan masukan dan saran sehingga makalah ini dapat diselesaikan dengan baik.

\section{Daftar Pustaka}

[1] A. Toruwich. 2005. Theory of Matrix. 6 ed. AGH. Krakow.

[2] Anton, H. 2005. Elementary Linier Algebra. Ninth Edition. Wiley. New York.

[3] Boyce,W.E. and Diprima,R.C.. 1999. Ordinary Differential Equations. Jhon Willey dan Sons, Inc. New York

[4] Lynch, Stephen. 2007. Dynamical Systems with Applications using Mathe- matica. Birkhäuser Boston, Cambridge.

[5] Murray, J. D. 1989. Mathematical Biology. Springer-Verlag Berlin Heidelberg. New York.

[6] Shonkwiler,R.W. and Hero, James. 1996. Mathematical Biology. Spinger. New York. 